\section{Organizational context variables to be considered in the reward system design oriented to product innovation}

\author{
Roberto Marx ${ }^{1}$ \\ Joáo Paulo Reis Faleiros Soares ${ }^{1}$ \\ Lidyane Stephane da Silva Barros ${ }^{1}$ \\ ${ }^{1}$ University of São Paulo, Polytechnic School, Production Engineering \\ Department, São Paulo, SP, Brazil
}

Received on

11/05/2015

Approved on

06/06/2016

\section{Responsible editor:}

Prof. Dr. João Maurício Gama

Boaventura

Evaluation process:

Double Blind Review

\begin{abstract}
Purpose - The main purpose of this paper is to discuss some key variables to be taken into consideration in an organizational context when designing reward systems focused on maximizing product innovation. In addition to identifying such variables, the paper aims to understand how each of them can influence this design.
\end{abstract}

Design/methodology/approach - Based on existing literature, a reference chart was created using context variables (organizational strategy, type of innovation, beliefs and cultural traits, and previously established systems of goals and rewards) and their implications on the reward system design. A field research was conducted through qualitative interviews with five specialists, consultants, and scholars in strategic human resource management and reward systems, as well as case studies on four largescale industrial companies known for being innovative.

Findings - The research has shown that little knowledge has been accumulated by specialists as well as by designers of reward systems at organizations operating in Brazil concerning the issue studied. Moreover, the four main previously listed variables were maintained, and the field research allowed a series of analyses that changed relevant aspects of the details of that chart.

Originality/value - This paper can contribute to fulfill the gap existing in literature on the reward system design, and proposes a reference chart that can assist the designer in elaborating it.

Keywords - Innovation process; product innovation; rewards for innovation.

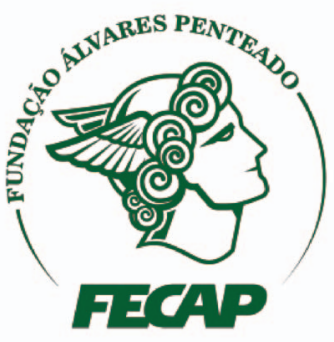

Review of Business Management

DOI:10.7819/rbgn.v18i60.2822 


\section{Introduction}

Strategies based on innovation and new product development have been increasingly used by organizations to offer more value to their customers, and thus to render them more competitive (Wheelwright \& Clark, 1992; Griffin, 1997; Rozenfeld et al., 2006; Lafley \& Charan, 2008). "In this conceptual progress context, it is crucial to understand in what way innovation management practices have been used, and to investigate the effectiveness of practices and how they (or their absence) refer to the obstacles faced by organizations when enhancing innovation." (Nagano, Stefanovitz, \& Vick, 2014, p. 165). As a result, studies in the area have also increased. One of the many aspects of this line of research addresses how companies provide incentives to their employees to innovate more and to achieve better results through the development of new products.

It is common for companies to offer their employees rewards to stimulate the effort and behaviors required to attain the company's key goals. This practice is based on several conceptual themes, such as agency theory (Fama, 1980; Eisenhardt, 1989a), and the so-called "strategic human resources management” (Holbeche, 2009; Dutra \& Hipolito, 2012; Bratton \& Gold, 2012).

In this context, the developers of a reward system that is focused on improving results through product innovation must ask a series of questions. One of the first topics of discussion is whether reward systems are truly effective in stimulating innovation in companies, or the very existence of stimuli for innovation actually works against the desired outcome, inhibiting it. There are studies that suggest that offering reward to generate innovation has no impact, or it can even decrease the innovative capacity of companies (Amabile, 1998; Burroughs, Dahl, Moreau, Chattopadhyay, \& Gorn, 2011). These studies suggest that by reinforcing rewards, companies induce many employees to abandon their desire to work on more challenging innovative ideas in order to invest on lower risk incremental innovation - and, consequently, increase their chances to receive more money.

Another relevant question is that if offering incentives for innovation is effective, what metrics should be used in the reward systems? Finally, one might also ask to which unit of analysis should such metrics, and the goals associated to them, be applied? In many studies, the innovation design team is the unit of analysis for defining goals and the consequent reward (Hoegl \& Parboteeah, 2003; Hamel, 2007; Davila, Epstein, \& Shelton, 2006, Maurer, 2010). However, this literature does not discuss whether the corporate system of goals and rewards uses the same unit of analysis to define the objectives, overlooking a key component in the design of a reward program.

Therefore, the main objective of this work is to discuss the key variables to be considered within the organizational context, in reward system designs focused on maximizing product innovation. As it will be exposed in section 4, there are many studies that address rewarding practices that promote innovation (Barczak, Griffin, \& Kahn, 2009; Baumann \& Stieglitz, 2014; Bourgeon, 2007; Calamel, Defelix, Picq, \& Retour, 2012; Davila et al., 2006; Jiang, Wang, \& Zhao, 2012; Goffin \& Mitchell, 2010; Hamel, 1999, 2007; Kunz, 2010, Jimenéz-Jiménez \& Sanz-Valle, 2008). However, few of them discuss how those practices adhere to each company's reality.

It is believed that the definition of a reward system is highly dependent on the context for which it is being designed, because, according to many authors, there is no reward system that is equally effective in any business context (Harris, 1997; Holbeche, 2009; Bratton \& Gold, 2012; Dutra \& Hipólito, 2012). Thus, the discussion being proposed here is relevant. The variables that were sought to identify in this work are related to conceptual and technical aspects, ignoring, for example, variables of a political nature or those involving power struggles within organizations. In addition, once the contextual variables are 
identified, it is also necessary to understand how each of them influences these designs. This is another objective of this work.

In order to conduct the aforementioned discussion, it was necessary to summarize fundamental concepts related to reward systems and innovative product development processes and organization. Later, an in-depth discussion about incentive practices and product innovation is offered. From these discussions based on the literature, a preliminary reference chart is presented, with the key organizational context variables that should be considered by a reward system and their implications for said system. Following, there was a discussion of the methodological approaches chosen for the field research, and their respective justifications. Evidence collected in the field is presented, analyzing the comments of five Human Resource (HR) and reward system specialists, as well as case studies on four companies recognized as innovators in Brazil, in order to refine the reference chart and draw the research conclusions.

\section{Reward systems: conceptual aspects}

The reward (or incentives) systems seek to observe and recognize how much an individual is worth to an organization, and are fundamental for attracting and retaining professionals (Dutra \& Hipólito, 2012). Rewards can be defined as any type of monetary, non-monetary, or psychological payment that an organization offers to its employees in exchange for work (Bratton $\&$ Gold, 2012).

Other fundamental roles of reward systems, however, are increasingly discussed in the literature. One of the main ones is the function of reinforcing organizational values and objectives (Holbeche, 2009), or whatever the organization wants to stimulate in its professionals, in order to encourage certain behaviors and actions. Following Cardoso (2006), alternatively to incentives derived from the position of the employee, reward systems can also be based on abilities and capabilities, being a motivation to develop those characteristics of workers and to recognize the individual efforts.

In the context of this study, this means that recognition and reward systems should emphasize attitudes and behaviors that support innovation, encourage teamwork, and emphasize the importance of innovation to the organization (Goffin \& Mitchell, 2010). Thus, it is already clear that the strategic orientation towards product innovation is a relevant contextual variable in reward system design.

Traditionally, the definition of the work contribution valuation was divided into two types of comparisons (Bratton \& Gold, 2012; Dutra \& Hipólito, 2012). The first, between valuation standards internal to the organization (reflecting and differentiating the contribution of each employee or group of employees to that specific company), and the second, between standards external to the organization (comparing the internal valuation standards to those practiced by other companies in similar situations). It is expected that these two forms of comparison should be governed by the principle of equity, from which a sense of fairness and justice is established on the part of the employee, regarding the reward offered.

Traditionally, the concept of position is adopted as a mechanism for valuing work (Dutra \& Hipólito, 2012). However, to offer rewards based on position alone can create a situation where professionals who contribute deferentially to the goals of the organization (whether through the quality of their work or through increased productivity, among other possibilities) are recognized in exactly the same way, leading to a sense of injustice that affects the commitment of the very employees who are most committed. In this context, models that favor both fixed and variable dimensions of compensation are gaining strength.

The compensation offered by a company to its employees may consist, generically, of the three following elements (Dutra \& Hipólito, 2012). 
a) Fixed remuneration - Fixed remuneration, essentially consisting of salary and benefits, is generally defined by organizations based on a set of job responsibilities and the expected complexity of the work, and is received on a regular basis. Salary is a simple form of compensation, representing the value attributed by the organization to the employees' work (Bratton \& Gold, 2009). Salary increase based on merit is a frequently used form of reward in the case of relevant contributions made by professionals to the business. The impact of this type of action on extrinsic motivation - type of motivation that comes from outside a person (Amabile, 1998) - is questionable (Harris, 1997). Based on this kind of questioning, by the way, the company's belief in the effectiveness of extrinsic motivators is a context variable that should be analyzed in the reward system design. In any case, within the context of this study, as long as the criteria for salary increases are related to elements linked to innovation, such increases can be considered in the design of a reward system aimed at providing incentive for innovation. Concerning benefits, there is no consistent evidence in the literature that they are significantly associated, at least on their own, to achieving a defined corporate strategy.

b) Variable remuneration - Variable remuneration is where payment depends on performance measured over a defined period of time (Harris, 1997). Many employees consider it to be a motivation, helping to clarify what the organization's most important goals, projects, and performance standards are. For this reason, variable remuneration, when well structured, is a powerful communication tool (Harris, 1997).

To define a program of variable remuneration, it is almost a prerequisite to define a system of indicators and goals upon which performance will be evaluated. According to Dutra and Hipólito (2012), currently, one way often used to define indicators and goals to be used in the process of performance management is to deploy the organizational objectives right down to the workgroup or employee level, using the Balanced Scorecard (BSC). One problem in the context studied here is that this deployment usually occurs in the functional units of the companies. Given the fact that innovation projects are often cross functional, the defined goals need to be aligned with the different areas, to ensure that the team members are evaluated on the performance of the innovation project. Despite this problem is rarely considered in the literature on innovation incentives, it is clear that, in order to propose new innovation rewards for a specific organization, one should understand the company's existing form of definition and deployment of the goals used in its reward systems.

Dutra and Hipólito (2012) also posed some questions that, if taken into account, can help to define the goals. Among the characteristics that the goals in a performance management system must have, they should be challenging but attainable, measurable and objective, relevant and time-bound ${ }^{2}$. The set of goals should be limited in number (as it is very difficult for an employee to try to achieve too many objectives at the same time). Another important consideration on the subject is that the practices induced by variable remuneration and the organizational culture must be adhered to. This is especially important when it comes to the unit of analysis of the variable remuneration (individual or collective). According to Bloisi (2007), the HR manager must understand the organizational culture, and recognize the values that the organization wants to foster.

c) Non-financial rewards - Besides the remunerative aspects, the reward system should also consider non-financial elements to increase its effectiveness. The importance of these aspects has grown, 
given changes in people's behavior and values (Holbeche 2009; Bratton \& Gold, 2009). Research suggests that motivating factors intrinsic to work perceived by the employees, like the chance to do something that makes sense both professionally and personally, or the opportunity to accelerate their development, which can be classified as non-financial rewards, are just as important as the financial package, since they represent "psychological" recognition for the work completed.

\section{The product innovation process and different forms of organization for innovation}

Product innovation occurs in companies following a process that, although it may be more or less structured, is relatively standardized. Song, Montoya-Weiss and Schmidt (1997) state that the new product development process can be viewed as a series of steps that include idea generation, product development, and marketing. Hansen and Birkinshaw (2007) present "the innovation value chain", offering their view of the product innovation process in a large organization. In this chain, the first step is the "idea generation", which may occur within or outside of the company, individually or collectively. This is followed by the "conversion" step, in which the ideas to be developed into new products are selected. The final step, called "diffusion", in which the new products are "disseminated" within the company to mobilize the efforts needed to launch the new product.

Another relevant author who addresses the new product development process is Robert Cooper, creator of the Stage Gates ${ }^{\oplus}$ methodology. According to this model (Cooper, 1994; Cooper, Edgett, \& Kleinschmidt, 2002), the development process involves several stages, the most important of which being idea filtering, scoping, building a business case, development, testing, validation, and launch. Between each of these stages there is a series of decision moments in which, using the information collected and the development observed in the previous step, a decision is made as to whether to go ahead with the project or not.

In larger companies, structured with a greater focus on innovation, most idea generation and experimentation that might lead to new products is entrusted to the Research and Development (R\&D) department (Wheelwright \& Clark, 1992). However, Davila et al., (2006), and Tidd, Bessant and Pavitt (2001) mention that idea generation is increasingly decentralized in companies, providing an opportunity for all employees in the organization to contribute to generating ideas (even though it might be considered utopian for everyone to be able to contribute equally in this sense).

However, at the beginning of the "conversion" phase in the Hansen and Birkinshaw (2007) model, new organizational changes are made that influence the design of the incentive system. Teamwork becomes more intense, increasing in complexity, and the mechanisms that generate alignment with the objectives become more relevant. There are various ways to organize product innovation project teams. Wheelwright and Clark (1992), in their important work, propose four principal forms of organizing new product development efforts.

The first form is the functional team, in which project participants are not taken out of their original departments. There is no specific project manager, and the coordination function is usually transferred from one functional manager to another over the life of the project. The functional leader evaluates and rewards the members of the team.

Another possible structure is the "lightweight team", with a single project manager responsible for the different phases of the initiative, facilitating interaction between members of the different departments, and transitioning activities. 
However, his or her activities are limited to monitoring the execution of the planned tasks, and keeping them on time and within budget. This role of the project manager does not overlap with that of the functional manager in the management of the professionals (or in the definition of their goals), who continue to work in their functional departments.

The third structure for innovation projects is the "heavyweight team", in which the project leader has direct access to and responsibility for the employees, even though they still report to their functional managers (who, in this case, have less power). Members of the project team usually work in the same physical location, together with the project leader, who offers relevant input for both the goal definition and performance evaluations of these professionals. This structure is more suitable for innovation projects that require intense technology changes, where the system is more important than a specific technical solution, and where the environment is dynamic, requiring integrated development.

Finally, the fourth form for structuring new product development teams is by means of autonomous teams. In this arrangement, which is suitable for radical innovation, the individuals are usually totally dedicated to the project and work in the same physical location. The project leader has total control over the project resources and professionals, with freedom to choose the team members, define their goals, perform their evaluations, and even to define the particular forms of rewards for the team.

The statements above suggest that, depending on the type of innovation desired, not only the form of work organization can vary, but also different reward practices can be applied. Therefore, the type of product innovation that the company wants to achieve might be another context variable to be observed in the definition of incentives for innovation.

\section{Preliminary context variables for the design of a reward system for innovation}

Based on the two previous sections, the literature specific to reward practices that aim to incentivize product innovation, whether in the idea generation phase or the conversion and diffusion phases of the Hansen and Birkinshaw (2007) model, was reviewed. A summary of the key points raised in this literature is given in Table 1 that is a consolidation of the main incentive practices for product innovation addressed by several authors. In this summary, relevant observations and considerations found in the literature are included. Following, in light of the literature reviewed so far, five key organizational context variables that should be considered in the design of a reward system focused on product innovation are proposed. These propositions will be further refined during field research.

\section{I Variable 1 - Strategic orientation towards product innovation}

If the organization has a strong strategic orientation towards product innovation the reward system should have elements that support the strategy with a focus on product innovation. In organizations where there is focus on innovation, it is important to systematically align the goals between the members of different areas participating in cross-functional teams. The compensation system in companies can adopt differentiated fixed remuneration (in relation to the internal and external public) process or qualitative evaluation that assesses behaviors or competencies for positions directly linked to the innovation and that support career decisions. Additionally, the organization can implement indicators linked to innovation in the performance appraisals that serve as the basis for variable remuneration or give opportunity for employees to work on projects relevant to innovation, with autonomy and enabling the exchange of knowledge. 
On other hand, if there is a weak or nonexistent strategic orientation towards product innovation, the reward system should have specificities that support other company strategies (i.e., it is not necessary to adopt elements like those listed above, which are mainly focused on incentivizing product innovation).

\subsection{Variable 2 - Type of product innovation that the company wants to achieve}

The type of innovation influences the settings of the reward system. If the organization is seeking innovation that is predominantly incremental, the reward system should be based on objective goals, with specific outcomes to be achieved in time, using the SMART concept

to define them. If the innovation is incremental and radical, the reward system should use simultaneously goals that follow the SMART concept (for incremental innovation projects) and open, subjective goals (for radical innovation projects), or be based on aggregate goals, assigned to the portfolio of innovation projects, to business unit results, or to those of the company. It is possible to adopt separate reward systems for radical innovation project teams, in parallel to the other corporate reward systems, or to place greater emphasis on fixed remuneration (for example, paying higher salaries for professionals involved with radical innovation) in relation to variable remuneration

\subsection{Variable 3-Beliefs and cultural traits}

This third variable relates to the organization's way of acting and thinking, as well as to what it believes in and values in its relationship with its employees. It is split into two components: Beliefs in the effectiveness of extrinsic motivators; and the value given to the financial results obtained from innovative products versus the value of achieving the operational goals of innovation projects.

If the company believes in the extrinsic motivators to use their different forms: merit increases, promotions, variable remuneration, and rewards linked to performance in innovation. But if there isn't the belief in these motivators, the system should emphasize intrinsic motivators, with little or no use of extrinsic motivators. Fixed remuneration for positions linked to the innovation process should be greater. 


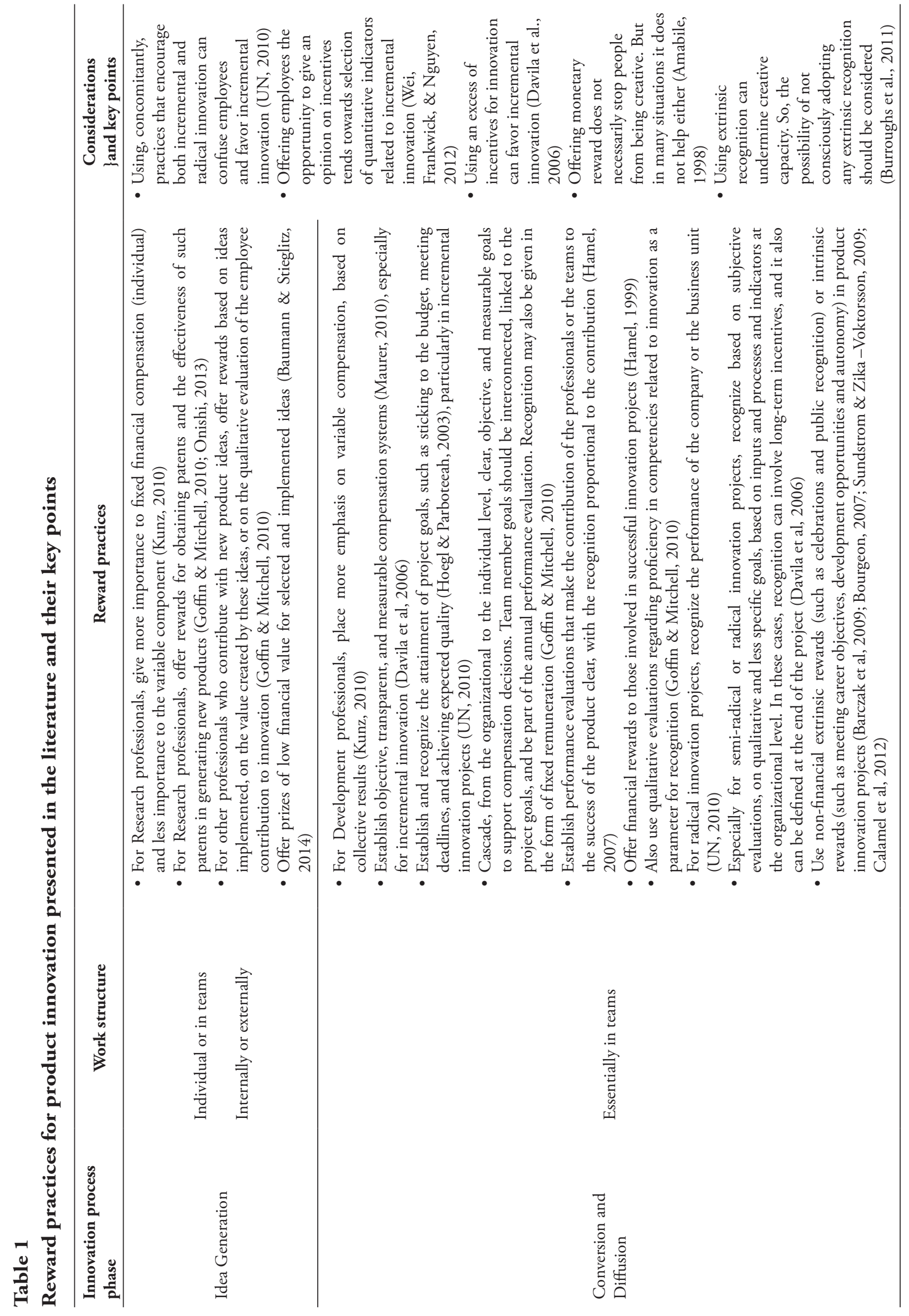


If the company values financial results generated by innovations, the goals used should base on the financial results generated by the innovation projects, results that are shared with the employees and that can deliver significant pay. However, if the company values achieving the operational targets of innovation projects the reward system should use goals based on the operational objectives of project (ex. meeting budget, timeframes, and quality specified). Compensation is not calculated based on the commercial results of the project.

\subsection{Variable 4-Previously existing goals and reward system}

Currently, most of big companies already have goal and reward system, regardless of whether their strategic directions are focused or not on product innovation. Therefore, the reward system designer who is planning a new system to incentivize product innovation should think about the already existing system of goals and rewards, so as to make the necessary adjustments, implementing new practices in harmony with those already in place, in an attempt to meet the desired new objectives.

In this context, it is necessary to consider the form of definition and deployment of goals used and the frequency of their revision. If there is already a goal assessment system in place that is not linked to rewards and that the company wants to use, the company should promote the linkage, compensating goals related to innovation. A full design of new goal and reward system will be necessary if there is no evaluation of goals. The form of definition and deployment of goals used in the reward system that can be linked to:

a) Corporate goals: Consider the aggregated contribution of innovation initiatives as a parameter for compensation by means of some thematic indicator. It will not be possible to reward specific projects;

b) Departmental goals: Provide a process of alignment of goals defined for all the departments involved in innovation projects; c) Individual goals for managers pushed down from corporate goals: Provide a process of alignment of goals defined for all the managers involved in the innovation projects;

d) Individual goals for managers not necessarily pushed down from corporate goals: Provide a process of alignment of goals defined for all the managers involved in innovation projects that is more intense and rigorous than the previous one;

e) Individual goals for employees pushed down from corporate goals: Provide a process of alignment of goals defined for all the employees involved in the innovation projects;

f) Individual goals for employees not necessarily pushed down from corporate goals: Provide a process of alignment of goals defined for all the employees involved in innovation projects that is more intense and rigorous than the previous one.

If it has been verified that in the company the revision of goals is performed every year or a little more than one year, the reward system should place greater weight on other elements that evaluate performance in innovation (like a qualitative evaluation), because few goals related to innovation will be assessed. However if the goals are revised within less than one year, the goals should be emphasized as one of the key elements for measuring the contribution to innovation, given that many goals related to the theme may be considered in the system.

\section{Research methodology}

The field research will seek to determine how experts and designers of incentive systems and programs for large industrial companies, operating in Brazil and focused on innovation, evaluate the organizational context variables addressed in the theoretic review conducted, in 
terms of their theoretic and empirical knowledge and their practical experience. Their comments will help refine the reference chart and lend greater robustness to the theoretical contribution of this work.

To select the experts to be interviewed, several criteria were established. We looked for professionals with significant professional experience (a minimum of 15 years of research and/or professional hands-on experience in strategic HR management), updated and aware of new trends in the field, as well as for individuals with a broad view of the market (consultants and scholars in the fields of strategic HR management or reward management).

Other criteria were used to select the companies to be investigated. We looked for companies for which the whole discussion so far makes sense. The selection criteria for companies to be investigated are summarized as follows:

a) To be considered a large-scale industry (i.e., with 500 or more employees, according to the industry criteria of the Brazilian Institute of Geography and Statistics (Instituto Brasileiro de Geografia e Estatistica, IBGE) and having more than 10 years of existence;

b) To be an industry with effective focus on product innovation, confirmed by the presence of at least two of the following evidences (commonly observed in innovation-driven organizations):

- The percentage of income derived from the sale of products launched within the last two years is higher than $25 \%$ in some of the operating segments;

- The percentage of annual sales targeted for $\mathrm{R} \& \mathrm{D}$ is higher than $1 \%$ (this value is above the Brazilian manufacturing industry average, according to (IBGE, 2011);

- The percentage of employees working directly on research activities is higher than $2 \%$;

- $R \& D$ resources have been funded by financing agencies (like Financiadora de
Estudos e Projetos, FINEP - a governmentowned company linked to the Ministry of Science and Technology) within the last three years;

- At least one external, relevant, public recognition (conferred by pertinent and reputed institutions, business magazines or academic journals) has been received for innovation in the last three years;

- Internal documents (like mission statements, vision, values, and innovation award programs, among others) are presented that explicitly disclose to the employees the strategic relevance of innovation for the company.

The application of these criteria to the universe of industrial companies (the focus of this study) operating in Brazil significantly reduces the size of the possible sample. In addition, the phenomenon being investigated was not often encountered in a structured format in the literature. Therefore, the most appropriate methodological approach to conduct this study was through qualitative research.

For Bryman (1989), the main characteristic of qualitative research is the perspective of the individual being studied. The investigator tries to extract what is important to the individuals, as well as their interpretations of the environment. In addition, qualitative research considers the unfolding of events over time. This approach is quite appropriate for the reality of this study. Semi-structured, qualitative interviews with the experts will seek to understand their perspectives and interpretations of the problem at issue, in a way that will bring new insights to the reference chart being refined.

The process of building theories from case studies proposed by Eisenhardt (1989b) was useful to orient the study being conducted, and was practically all followed. In this work, semistructured interviews will also be conducted in companies with professionals responsible for the design and management of reward systems. 
The scripts for the interviews with experts and company professionals were structured to enable collection of the information required for a critical analysis of the prepared reference chart. The scripts contained questions related to all context variables described in the preliminary reference chart. Open-ended questions were mainly used.

Adhering to the selection criteria presented, a preliminary list of 13 experts was created and an attempt was made to contact them. However, not all of them answered to the contact or agreed to take part of the research. Then, five interviews were conducted, each lasting between an hour and two hours and a half.

In the case of the companies, the initial selection of companies to be contacted was made using academic publications and business magazines, exploring organizations that stand out for their innovation. From a preliminary list of 14 companies that met the criteria for participation in the research, and that was attempted to contact, 4 agreed to participate in the study. Interviews with employees of these companies lasted between forty-five minutes and two hours.

\section{Characterization of companies and interviewees}

Two tables with the key data collected in the interviews with the experts and the companies researched are presented below. To protect the identity of both experts and companies (a condition stipulated by several of the interviewees to be able to participate in the research), the names and any data that might facilitate certain identification have been omitted. The specialists will be represented by a letter, A through E, while the companies will be represented by a number from 1 to 4 .

The group of experts is made up of four consultants and a professor. The four consultants (experts A, C, D, and E) have professional experience ranging from 15 to 35 years, hold positions as partner or director, and all have relevant experience in strategic $\mathrm{HR}$ management projects and/or strategic reward. Specialist B is a professor and researcher of one of the country's major universities, giving MBA courses in the field of people management.

Company 1 produces consumer goods and pharmaceuticals and has over 10,000 employees. In 2011, the company directed its strategy towards organic growth, where product innovation is essential. In the pharmaceutical division, the company had more than two hundred products under development during the first quarter of 2014, with eight new products launched during that period. In the consumer division, in 2013 the company reached $50 \%$ of its "innovation index", an indicator that measures the percentage of sales derived from products launched in the past two years.

Company 2 is operating in the chemical sector for more than 40 years. In 2013, it had more than 1,500 employees. The company strategy is based mainly on differentiation through new product development, and on a vision of sustainability. It invests around $1.5 \%$ of its annual sales in R\&D. In 2011, it submitted seven patent applications. Almost $6 \%$ of its employees are directly involved in the development of new products and processes. The company has been using FINEP financing for over a decade.

Company 3 is a Brazilian multinational in the food sector, with tens of thousands of employees. A significant expansion of the product portfolio to align with the habits of customers here and abroad is one of the central aspects of its internationalization strategy. The company has an innovation center occupying an area of more than $10,000 \mathrm{~m}^{2}$ where more than 250 employees work. For this center alone, the company received around thirty million dollars from FINEP. In the past two years, more than 600 new products have been launched. Because of its focus on innovation, it was recognized as one of the world's 100 most innovative companies by one of the planet's most important business magazines in 2012 and 2013. 
Company 4 operates in packaging and has 1,000 employees. The company is highly focused on innovation and has won numerous prizes in this area. For the past five years, it has been listed as one of the most innovative Brazilian companies in a survey published by one of the country's leading business magazines. In its strategic map linked to the BSC, its mission, its vision, and its values, innovation is a theme that is explicitly explored.

\section{Analysis of qualitative interviews and cases studies}

The interviews with experts and case studies conducted on the companies led to significant progress in the discussion needed to refine the reference chart under preparation, confirming aspects addressed earlier, bringing important counterpoints to the table, and even adding new elements to it. Next, each variable in the reference chart will be discussed, incorporating the key reflections captured in the field research, in order to arrive at the refined version.

\section{I Strategic orientation towards product innovation}

The importance of the reward system taking the strategic orientation towards innovation into account is unanimously emphasized by the experts, despite the fact that it was only clearly observed in company 4. Furthermore, the use of a "market practice" focused on short-term delivery, and on the concretization of the concept of "meritocracy", was prevalent.

The fact that the innovation strategy has little influence on the reward system in companies 1,2 , and 3 does not appear to be a conscious choice on the part of its designers, but rather the adoption of a universalist approach to analysis.
Despite this reality in three of the companies researched, and bearing in mind the supporting literature, the arguments of the experts, and the presence of a practical case in which the strategic orientation towards innovation was in fact considered in the reward system design, this variable is considered fundamental to the design of a reward system.

Elements suggested in the preliminary reference chart that can be adopted to support strategic orientation towards innovation, such as the use of qualitative evaluations that reinforce competencies linked to innovation, the adoption of indicators linked to innovation, and the alignment of goals among the different areas that participate in the innovation project, were extensively discussed in the field work. This fact supports maintaining them in the reference chart. According to some arguments presented in the literature (Dutra \& Hipolito, 2012; Goffin \& Mitchell, 2010), fixed remuneration is a tool to reinforce the importance of innovation so it was kept in the reference chart, although it was the only point that did not come up in the discussions with the experts and the companies.

The propositions made in section 4 about the first organizational context variable were confirmed for the reasons described above. Table 2 is a schematic representation of the key elements to be considered in the reward system linked to strategic orientation towards product innovation.

\subsection{Type of product innovation that the company wants to achieve}

This variable was viewed from different perspectives by the experts (although from their comments, it appears that there is agreement as to its importance), while the cases studied provided few elements for analysis. 
Table 2

Schematic representation of the variable "Strategic orientation towards product innovation" and its implications for the design of a reward system

Organizational Context Variable 1:

Strategic orientation towards product innovation

If the organization has...

A strong strategic orientation towards product innovation
A weak or non-existent strategic orientation towards product innovation
The reward system should...

Present elements that support the strategy with a focus on product innovation, such as:

- Differentiated fixed remuneration (in relation to the internal and external public) for positions directly linked to the innovation process

- Qualitative evaluation that assesses behaviors or competencies linked to innovation and that support career decisions

- Adoption of indicators linked to innovation in the performance appraisals that serve as the basis for variable remuneration;

- Systematic alignment of goals between the members of different areas participating in cross-functional teams

- Opportunity for employees to work on projects relevant to innovation, with autonomy and enabling the exchange of knowledge

Present specificities that support other company strategies (i.e., it is not necessary to adopt elements like those listed above, which are mainly focused on incentivizing product innovation)
In the interviews with the experts, the argument that the same reward system can be used to incentivize both incremental and radical innovation was proposed, only being necessary to adjust the performance indicators evaluated to differentiate the recognition of the projects (as opposed to what was included in the preliminary reference chart). However, the reality of the companies suggested some attention to this aspect. Even though the reward systems in companies 1, 2, and 3, are based exclusively on the definition of goals following the SMART concept, and are apparently being adapted to incentivize incremental innovations, there are indications that these systems would not be suitable to evaluate and reward radical innovation.

This assertion, strongly and consistently backed by arguments presented in the literature mainly in Davila et al. (2006), which were seen as relevant by one of the designers interviewed, suggests that the modeling of the system cannot follow exactly the same parameters for both types of innovations. This being so, the possibility raised by several experts that exactly the same system of goals and rewards could be used for both types of innovation (changing only the goals) and would alter the preliminary reference chart, will not be considered.

As previously mentioned, fixed remuneration favoring professionals involved in radical innovation was not observed, either among the interviewees or the companies studied. Nevertheless, the arguments in the literature are quite robust and were not opposed. Thus, it was decided that this alternative would also be maintained in the refined reference chart.

Despite the whole discussion developed above, the preliminary propositions made from literature in section 4 did not change. The schematic representation of the second organizational context variable is in Table 3 . 
Table 3

Schematic representation of the variable "Type of product innovation that the company wants to achieve" and its implications for the design of a reward system

Organizational Context Variable 2:

Type of product innovation that the company wants to achieve

If the organization is seeking innovation that is...

Predominantly incremental

Incremental and radical

\author{
The reward system should...
}

Be based on objective goals, with specific outcomes to be achieved in time, using the SMART concept to define them

- Use simultaneously goals that follow the SMART concept (for incremental innovation projects) and open, subjective goals (for radical innovation projects), or

- Be based on aggregate goals, assigned to the portfolio of innovation projects, to business unit results, or those of the company, or

- Adopt separate reward systems for radical innovation project teams, in parallel to the other corporate reward systems, or

- Place greater emphasis on fixed remuneration (for example, paying higher salaries for professionals involved in radical innovation) in relation to variable remuneration

\section{$7 \cdot 3$ Beliefs and cultural traits}

In terms of the beliefs and cultural traits that influence the design of a reward system, one component that was not addressed explicitly in the preliminary reference chart came out quite strongly, both in the qualitative interviews with the experts and the case studies: the value of individual recognition versus the value of collective recognition. This, incidentally, is perhaps one of the strongest contributions of the field research to the reference chart.

The experts are practically unanimous in saying that for innovation to flourish in the organization, it must stimulate cooperative behavior. However, many companies are trying to emphasize meritocracy, moving towards an individualization of compensation. In this context, if the company also wants to incentivize innovation, it must include balances in the reward system that affirm that, while individual delivery is important, delivery cannot be "at any cost", i.e., without collective delivery and collaboration.

Thus, in general, the preliminary reference chart underwent an important change in the variable "beliefs and cultural traits" which is the introduction of the component "orientation towards individual recognition vs. orientation towards collective recognition". The other elements, which were not widely discussed in the interviews and cases, were not opposed and were kept. Table 4 is a schematic representation of the version of the referenced variable. 
Table 4

Schematic representation of the variable "Beliefs and cultural traits" and its implications for the design of a reward system

\begin{tabular}{|c|c|}
\hline \multicolumn{2}{|r|}{$\begin{array}{l}\text { Organizational Context Variable 3: } \\
\text { Beliefs and cultural traits }\end{array}$} \\
\hline \multicolumn{2}{|c|}{$\begin{array}{l}\text { Component } 1 \text { : } \\
\text { Focus on individual recognition vs. focus on collective recognition }\end{array}$} \\
\hline If the company is... & The reward system should... \\
\hline Focused on individual recognition & $\begin{array}{l}\text { Contain elements that make a counterpoint to the focus on individual recognition, } \\
\text { explaining the relevance of also favoring teamwork. Examples of these elements are: } \\
\text { - The use of collective goals as important input to variable remuneration (in parallel to } \\
\text { individual goals that may possibly already be in use), or } \\
\text { - The use of qualitative evaluation (with behaviors related to innovation) as a significant } \\
\text { impact to fixed and/or variable compensation }\end{array}$ \\
\hline $\begin{array}{l}\text { Focused on collective } \\
\text { recognition }\end{array}$ & $\begin{array}{l}\text { Disregard the need to adopt elements exclusively to make a counterpoint to the emphasis on } \\
\text { individual recognition }\end{array}$ \\
\hline \multicolumn{2}{|r|}{$\begin{array}{l}\text { Component } 2 \text { : } \\
\text { Belief in the effectiveness of extrinsic motivators }\end{array}$} \\
\hline If the company... & The reward system should... \\
\hline $\begin{array}{l}\text { Believes in the effectiveness of } \\
\text { extrinsic motivators }\end{array}$ & $\begin{array}{l}\text { Use extrinsic motivators in their different forms (merit increases, promotions, variable } \\
\text { remuneration, and rewards linked to performance in innovation) }\end{array}$ \\
\hline $\begin{array}{l}\text { Does not believe in the effectiveness } \\
\text { of extrinsic motivators }\end{array}$ & $\begin{array}{l}\text { Emphasize intrinsic motivators, with little or no use of extrinsic motivators. Fixed } \\
\text { remuneration for positions linked to the innovation process should be greater }\end{array}$ \\
\hline \multicolumn{2}{|c|}{$\begin{array}{c}\text { Component } 3: \\
\text { Valuing financial results vs. Valuing reaching operational goals } \\
\end{array}$} \\
\hline If the company... & The reward system should... \\
\hline $\begin{array}{l}\text { Values financial results generated by } \\
\text { innovations }\end{array}$ & $\begin{array}{l}\text { Use goals based on the financial results generated by the innovation projects, results that are } \\
\text { shared with the employees and that can deliver significant pay }\end{array}$ \\
\hline $\begin{array}{l}\text { Values achieving the operational } \\
\text { targets of innovation projects }\end{array}$ & $\begin{array}{l}\text { Use goals based on the operational objectives of project (ex. meeting budget, timeframes, } \\
\text { and quality specified). Compensation is not calculated based on the commercial results of } \\
\text { the project }\end{array}$ \\
\hline
\end{tabular}

\subsection{Previously existing goals and reward system}

The analysis of a company's preexisting system of goals and incentives in the design of a reward system is another point around which there were few differences. It is true that two of the experts felt that the existing system should be adapted to include incentives for innovation, while one advocated the adoption of a totally new system. However, it is clear that the analysis of this system (and, according to the experts, the qualitative evaluation as well) is fundamental to deciding whether or not it will be harnessed, and if harnessed, which aspects need to be adjusted to include incentives for innovation. Table 5 is the schematic representation of the variable "Previously existing goals and reward system" after refinement. 
Table 5

Schematic representation of the variable "Previously existing goals and reward system" and its implications for the design of a reward system

\begin{tabular}{ll}
\hline $\begin{array}{l}\text { If it has been verified that in the company } \\
\text { there are... }\end{array}$ & $\begin{array}{c}\text { Organizational Context Variable 4: } \\
\text { Previously existing goals and reward system }\end{array}$ \\
\hline $\begin{array}{l}\text { The reward system should... } \\
\text { organization }\end{array}$ & $\begin{array}{l}\text { - If there is already a goal assessment system in place that is not linked to rewards and } \\
\text { that the company wants to use, promote the linkage, compensating goals related to } \\
\text { innovation } \\
\text { If there is no evaluation of goals, or if the company does not want to use the existing } \\
\text { system, design a new system (preferably simple to use at the beginning, with future } \\
\text { sophistication) }\end{array}$ \\
\hline $\begin{array}{l}\text { Rewards linked to corporate } \\
\text { Goals }\end{array}$ & $\begin{array}{l}\text { Consider the aggregated contribution of innovation initiatives as a parameter for } \\
\text { compensation by means of some thematic indicator. It will not be possible to reward } \\
\text { specific projects }\end{array}$ \\
\hline $\begin{array}{l}\text { Rewards linked to departmental goals } \\
\text { Provide a process of alignment of goals defined for all the departments involved in } \\
\text { innovation projects }\end{array}$ \\
\hline $\begin{array}{l}\text { Rewards linked to individual goals for } \\
\text { employees }\end{array}$ & $\begin{array}{l}\text { Provide a process of alignment of goals defined for all the managers involved in the } \\
\text { innovation projects }\end{array}$ \\
\hline
\end{tabular}

The discussion about the need for alignment of goals functionally deployed in the context of innovation, which is little covered in the literature, was identified as fundamental, and will therefore be maintained with timely adjustments. Contingencies related to the individual goals of the system, whether or not resulting from the deployment of corporate goals, were excluded, as this distinction was deemed to be of no practical relevance. The discussion about the frequency of the revision of goals in the compensation system was considered not relevant after the field research, because the companies have mechanisms to adjust the defined goals, permitting the addition of new relevant goals during the year as needed.
For this reason, this component was removed. Finally, one more significant contribution is added to the refined reference chart, mainly given by the experts, who spoke about a series of surrounding conditions, which, while they do not directly affect the design of a reward system, are important for a successful implementation. Besides being relevant from a conceptual point of view, these conditions were also often considered in the cases studied, giving them consistency. This set of key success factors for the design of a reward system targeting innovation is summarized in Table 6 , completing the refinement of the reference chart prepared in this study. 
Table 6

Key success factors for the implementation of a reward system targeting innovation

Key Success Factors for the Implementation of a Reward system targeting Innovation

- Genuine intention of the company to innovate, represented mainly by senior management support for this purpose

- Availability of information systems and personnel dedicated to the administration of the reward system. This system requires monitoring and adjustment over time, which requires the effort of the organization

- Alignment of the other HR processes and practices around the strategic objective of innovation, among them attracting people intrinsically motivated to innovate, training, and the creation of an environment suitable for innovation. All the HR systems must reinforce the same messages to the employees

- Strong involvement from low- and mid-level management in the design and/or implementation of the system, so as not to generate resistance, but rather, to support the system changes

- Preparation of the employees for a higher level of use of risk rewards, given that the process of innovation involves risk by nature

- Change management, through actions like broad and transparent communication, training, and impact analysis, which will be used continuously in the management of the new reward system

\section{Conclusions}

This study sought to present a reference chart of organizational context variables and their implications to be taken into account in the design of a system to reward innovation. The intention to build the reference chart came from the fact that the literature, as reviewed on section 4 , mostly focused on isolated reward practices. In this context, the existing literature as mentioned in the introduction of this paper presents a series of limitations regarding this theme, such as the use of innovation project team as the main unit of analysis in the definition of reward practices by the company (Hoegl \& Parboteeah, 2003; Hamel, 2007; Davila et al., 2006; Maurer, 2010). For the most part, there is no discussion about the concept that these practices should include organizational context variables (such as the company's existing reward system), restricting their adherence to the reality of the organizations.

The functional characteristics of such systems, as well as the strategic objectives related to innovation, and the beliefs and culture of the organization, are little explored in the literature that addresses incentives for innovation, which leads to disregard the influence that these elements have on the design of a reward system for innovation.

The refined reference chart of variables and implications presented at the end of the previous section, which has four main variables, is the first step towards a more comprehensive look at the design of a system or a scheme of rewards targeting innovation. Instead of analyzing "best reward practices" (approach used by Hamel, 2007, for instance), a different approach was adopted, discussing how reward practices adhere to different organizational contexts. In addition to believing that the discussion conducted in this work contributes to narrowing the gap identified in the literature, though slightly, the authors also believe that the reference chart proposed here can assist the designer in elaborating a reward system for innovation.

The discussion of each variable and its implications, which was the main purpose of this paper, is a first step towards reflection, even if not definitive, for the designer seeking a more adequate solution for a company. However, other considerations deserve to be made. It was clear that the topic is still in its very early stages, at least in the Brazilian context. Renowned experts and designers have little involvement with the theme "rewards for innovation" in day-to-day work. Moreover, in three of the four companies investigated, the strategy for product innovation was only loosely connected and weakly supported by the reward system. Starting with the premise that reward systems should communicate what is expected from employees in order to meet organizational objectives, there are two possible explanations. Either innovation is not, in reality, a priority to be emphasized to employees by 
means of these systems, or else a series of noises or difficulties inside the organization prevent it from being duly considered in the design.

Despite the contribution given by this research, it has some limitations. More in-depth discussions leading to the reference chart prepared should be conducted if access to more companies becomes feasible since access to the companies was one of the major challenges of this research.

Observation of companies in sectors that invest more in $\mathrm{R} \& \mathrm{D}$ in Brazil is a good opportunity for future studies. In addition, a few other possibilities for future study include conducting a study with companies in other sectors, notably service sector; observing not only companies of national origin (that for reasons of access ended up comprising the set of companies observed), but also companies in countries that invest more heavily in innovation.

This is possible, researching companies of different sizes and stages of maturity (such as start-ups, not included in this study, or even small- or medium-sized companies focused on innovation). Another potential study is more deeply analyzing the variables presented here, and exploring possible relationships between them. The variables obtained in this study can be combined in different ways to structure different reward systems, even if they are all focused on incentivizing product innovation. Exploring these combinations offers ample space for new research.

It is believed, therefore, that this work represents an initial foray into this subject from the proposed perspective. Its primary objective was to advance the theme, exploring elements little considered in the literature, as well as to systematize discussions, previously sparse, an objective that was accomplished.

\section{Notes}

1 Chiavenato (2004) considers the terms "reward" and "incentive" to be synonyms in the organizational context. At several points in this paper, the same consideration will be adopted.
2 These characteristics derive from a concept, widespread in the market, whereby "SMART" goals should be defined. "SMART", in this case, is an acronym formed by the initials of words that describe a well-defined goal: Specific, Measurable, Attainable, Relevant, and Timebound.

\section{References}

Amabile, T. (1998). How to kill creativity. Harvard Business Review, 76(5), 76-87.

Barczak, G., Griffin A., \& Kahn, K. B. (2009). Perspective: Trends and drivers of success in NPD practices: Results of the 2003 PDMA best practices study. Journal of Product Innovation Management, 26(1), 3-23.

Baumann, O., \& Stieglitz, N. (2014). Rewarding value-creating ideas in organizations: The power of low-powered Incentives. Strategic Management Journal, 35(03), 358-375. Retrieved from http:// onlinelibrary.wiley.com/doi/10.1002/smj.2093/ abstract. doi: 10.1002/smj.2093

Bloisi, W. (2007). An introduction to buman resource management. Maidenhead: McGraw-Hill.

Bourgeon, L. (2007). Staffing approach and conditions for collective learning in project teams: The case of new product development projects. International Journal of Project Management, 25(4), 413-422. Retrieved from http://www.sciencedirect.com/science/article/ pii/S0263786307000312. doi:10.1016/j. ijproman.2007.01.014

Bratton, J., \& Gold, J. (2012). Human resource management: Theory and practice (5th ed.). Basingstoke: Palgrave Macmillan.

Bryman, A. (1989). Research methods and organization studies. London: Routledge.

Burroughs, J. E., Dahl, D. W., Moreau, C. P., Chattopadhyay, A., \& Gorn, G. J. (2011). Facilitating and rewarding creativity during new product development. Journal of Marketing, 
75(4), 53-67. Retrieved from http://journals.ama. org/doi/abs/10.1509/jmkg.75.4.53. doi: http:// dx.doi.org/10.1509/jmkg.75.4.53

Calamel, L., Defelix, C., Picq, T., \& Retour, D. (2012). Inter-organizational projects in French innovation clusters: The construction of collaboration. International Journal of Project Management, 30(1), 48-59. Retrieved from http://www.sciencedirect.com/science/article/ pii/S0263786311000342. doi:10.1016/j. ijproman.2011.03.001

Cardoso, L. (2006). Avaliando sistemas de remuneração baseados em habilidades e competências: A visão dos profissionais de gestão de pessoas. Revista Brasileira de Gestão de Negócios, 8(21), 13-23.

Chiavenato, I. (2004). Gestão de pessoas. Rio de Janeiro: Campus.

Cooper, R. G. (1994) Perspective: Thirdgeneration new product processes. Journal of Product Innovation Management, 11(1), 3-14. Retrieved from https://www.researchgate.net/ publication/222050288_Third_Generation_ New_Product_Process. doi: 10.1016/07376782(94)90115-5

Cooper, R. G., Edgett, S. J. \& Kleinschmidt, E. J. (2002) Optimizing the stage-gate process: What best-practice companies do - Part One. ResearchTechnology Management, 45(5), 21-27.

Davila, T., Epstein, M. J., \& Shelton, R. (2006). Making innovation work: How to manage it, measure it, and profit from it. New Jersey: Prentice Hall.

Dutra, J. D., \& Hipólito, J. A. M. (2012). Remuneração e recompensas. Rio de Janeiro: Elsevier.

Eisenhardt, K. M. (1989a) Agency theory: An assessment and review. Academy of Management Review, 14(1), 57-74.
Eisenhardt, K. M. (1989b). Building theories from case study research. Academy of Management Review, 14(4), 532-550.

Fama, E. (1980). Agency problems and the theory of the firm. Journal of Political Economy, 88(2), 288-307.

Goffin, K., \& Mitchell, R. (2010). Innovation management: Strategy and implementation using the pentathlon framework (2nd ed.). Basingstoke: Palgrave Macmillan.

Griffin, A. (1997). PDMA research on new product development practices: Updating trends and benchmarking best practices. Journal of Product Innovation Management, 14(6), 429-458. Retrieved from http://www.sciencedirect.com/ science/article/pii/S0737678297000611. doi: 10.1016/S0737-6782(97)00061-1

Hamel, G. (1999). Bringing Silicon Valley inside. Harvard Business Review, 77(5), 71-85.

Hamel, G. (2007). The future of management. Boston: Harvard Business School Press.

Hansen, M. T. \& Birkinshaw, J. (2007). The innovation value chain, Harvard Business Review, 85(6), 121-130.

Harris, M. (1997). Human resource management: A practical approach. Orlando: Harcourt Brace \& Company.

Hoegl, M., \& Parboteeah, K. P. (2003). Goal setting and team performance in innovative projects: On the moderating role of teamwork quality. Small Group Research, 34(1), 3-19. Retrieved from https://www.researchgate.net/ publication/41463921_Goal_Setting_And_ Team_Performance_In_Innovative_Projects. doi: $10.1177 / 1046496402239575$

Holbeche, L. (2009). Aligning human resources and business strategy (2nd ed.). Oxford: ButterworthHeinemann. 
Instituto Brasileiro de Geografia e Estatística. (2011). Relatório PINTEC - Pesquisa de inovação tecnológica. Retrieved from http://www.ibge. gov.br/home/estatistica/economia/industria/ pintec/2011/default.shtm.

Jiang, J., Wang, S., \& Zhao, S. (2012). Does HRM facilitate employee creativity and organizational innovation? A study of Chinese firms. International Journal of Human Resource Management, 23(19), 4025-4047. Retrieved from http://www.tandfonline.com/ doi/abs/10.1080/09585192.2012.690567 doi: $10.1080 / 09585192.2012 .690567$

Jimenéz-Jimenéz, D., \& Sanz-Valle, R. Could HRM support organizational innovation? (2008). International Journal of Human Resource Management, 19(7), 1208-1221. Retrieved from http://www.tandfonline.com/ doi/abs/10.1080/09585190802109952. doi: $10.1080 / 09585190802109952$

Kunz, J. (2010). Performance evaluation in multistep processes: A comparison of evaluation types with special emphasis on R\&D. IEEE Transaction on engineering management, 57(3), 405-415. Retrieved from http://ieeexplore.ieee.org/xpl/login. jsp?tp=\&arnumber $=5416313 \&$ url $=$ http $\% 3 A \% 2$ F\%2Fieeexplore.ieee.org\%2Fxpls\%2Fabs_all. jsp\%3Farnumber\%3D5416313. doi: 10.1109/ TEM.2010.2040744

Lafley, A. G., \& Charan, R. (2008). The gamechanger. New York: Crown Business.

Maurer, I. (2010). How to build trust in inter-organizational projects: The impact of project staffing and project rewards on the formation of trust, knowledge acquisition and product innovation. International Journal of Project Management, 28(7) 629-637. Retrieved from http://www.sciencedirect.com/science/ article/pii/S0263786309001367. doi:10.1016/j. ijproman.2009.11.006

Nagano, M. S., Stefanovitz, J. P., \& Vick, T. E. (2014). Characterization of brazilian industrial companies' processes and challenges as to innovation management. Revista Brasileira de Gestão de Negócios, 16(51), 163-179.

Retrieved from https://rbgn.fecap.br/RBGN/ article/view/1426/pdf_58. doi: http://dx.doi. org/10.7819/rbgn.v16i51.1426

Rozenfeld, H., Forcellini, F. A., Amaral, D. C., Toledo, J. C., Silva, S. L., Alliprandini, D. H, ... Scalice, R. K. (2006). Gestão de desenvolvimento de produtos: Uma referência para a melhoria do processo. São Paulo: Saraiva.

Song, X. M., Montoya-Weiss, M. M., \& Schmidt, J. B. (1997). Antecedents and consequences of cross-functional cooperation: A comparison of $\mathrm{R} \& \mathrm{D}$, manufacturing and marketing perspectives. Journal of Product Innovation Management, 14(1), 35-44. Retrieved from http://onlinelibrary.wiley. com/doi/10.1111/1540-5885.1410035/abstract. doi: 10.1111/1540-5885.1410035

Sundstrom, P., \& Zika-Viktorsson, A. (2009). Organizing for innovation in a product development project: Combining innovative and result oriented ways of working - a case study. International Journal of Project Management, I(8) 745-753. Retrieved from http://www.sciencedirect.com/science/article/ pii/S0263786309000192. doi: 10.1016/j. ijproman.2009.02.007

Tidd, J., Bessant, J. \& Pavvitt, K. (2001). Managing innovation: Integration technological, market and organizational change (2nd. ed.). Chichester: John Willey \& Sons.

Un, C. A. (2010). An empirical multilevel analysis for achieving balance between incremental and radical innovations. Journal of Engineering and Technology Management, 27(1), 1-19. Retrieved from https://www.researchgate. net/publication/245218985_An_Empirical_ Multi-Level_Analysis_for_Achieving_Balance_ between_Incremental_and_Radical_Innovations. doi:10.1016/j.jengtecman.2010.03.001 
Wei, Y. Frankwick, G. L. \& Nguyen, B. H. (2012). Should firms consider employees input in reward decisions? Participation effect on market orientation and new product performance. The Journal of Product Innovation Management, 29(4), 546-558. Retrieved from http://onlinelibrary.wiley.com/doi/10.1111/ j. $1540-5885.2012 .00924 . x / a b s t r a c t$. doi: $10.1111 /$ j.1540-5885.2012.00924.x

Wheelwright, S. C., \& Clark, K. B. (1992). Revolutionizing product development: Quantum leaps in speed, efficiency and quality. New York: The Free Press.

\section{Appendix A - Interview Guide: Experts}

1. Assuming that launching innovative products is important for an organization, do you think it makes sense to have a reward system or a reward program to encourage product innovation? Why?

2. [If the answer for the previous question is no] In this case, what should be the main features of the reward system of a company that focus on product innovation? What should the reward system encourage in this case?

3. [If the answer for the previous question is yes] In this case, what variables concerning the internal context of the organization (such as decisions or systems previously adopted by the company, characteristics and beliefs) a designer should understand to design a reward system that intend to encourage product innovation? Why?

4. How do you believe the variables presented in the previous question's answer influence the reward system? That is, how such variables must be taken into account in the system design?

5. What variables do you think should not be considered in the reward system to encourage innovation in products?

6. Do you believe the corporate strategy is an important variable to be considered in this context? Why? If so, how do you believe that this variable influences the system design?

7. Do you believe that the kind of innovation (incremental or radical ${ }^{*}$ ) that the company wants to encourage is an important variable to be considered in this context? Why? If so, how do you believe that this variable influences the system design?

8. Do you believe that the beliefs and assumptions of the organization (especially those related to the manner of rewarding employees), or the organizational culture itself, represent an important variable to be considered in this context? If so, what beliefs or cultural aspects most influence system design, and how do you think they influence the system design?

9. Do you believe that the existing goals and incentives system in the organization is an important variable to be considered in this context? Why? If so, how do you believe that this variable influences the system design?

10. Did you remember, during the interview, any other important variable that a designer of a reward system should seek to understand to design a reward system to encourage innovation in an organization? If so, what is this variable and why is it important?

11. Do you know cases of specific reward systems for innovation? If so, please describe how this system is (or was).

* If necessary, explain the concepts of incremental or radical innovation adopted in the research. 


\section{Appendix B - Interview Guide: Professional from the Researched Companies}

1. Does your company have a reward system or exclusively oriented reward program to encourage innovation in products? Why?

2. [If the answer for the previous question is no] What are the main features of the company's reward system? What it seeks to encourage? And taking into account that this is an innovation-driven organization, does it intends to adopt a reward system focused on product innovation?

3. [If the answer for the previous question is yes] What are the main features of the company's reward system, and, especially, what rewards are offered specifically to encourage product innovation?

4. [If the answer for the previous question is yes] What variables on the internal context of the organization (such as decisions or systems previously adopted by the company, characteristics and beliefs) were considered in the design (or redesign) of the reward system to encourage innovation in products? Why such variables were considered?

5. Do you believe that any relevant variable was not considered in the design (or redesign) of the current system? If so, what was that variable and why do you think it is important? And why it was not considered?

6. Does the company have a product innovation strategy? Please, explain. Do you believe that this strategy influences the design of the reward system that seeks to encourage innovation in products? Why?

7. What kind of innovation the company favors (incremental or radical*)? Please, explain. Do you believe that the kind of innovation that the company pursues influences the design of the reward system that seeks to encourage innovation in products? Why?

8. Does the company believes in the effectiveness of extrinsic motivators **? Please, explain. Do you believe that this variable influences the reward system design? Why?

9. Does the company seeks to reward actual financial results of their projects, or compliance with its operational goals (for instance: deadlines accomplishment, cost or quality)? Please, explain. Do you believe that this variable influences the reward system design? Why?

10. How is the goals and incentives system of the company? Do you believe that the characteristics of this system influence the reward system design? Why?

11. Is the variable compensation system linked to the company's performance appraisal process? If so, what is the basis of the company's performance appraisal? Do you believe that this variable influences the reward system design? Why?

12. If the company adopts a reward system focused on innovation, was there a consulting partner involved in the system design and / or implementation? Which was the contribution of this consulting firm?

13. Do you know other companies that have specific reward systems focusing on innovation? If so, please describe which are the main characteristics of this system.

* If necessary, explain the concepts of incremental or radical innovation adopted in the research.

** If necessary, explain the concepts of extrinsic motivation and intrinsic motivation adopted in the research. 


\section{Supporting agencies:}

CNPq - Conselho Nacional de Desenvolvimento Científico e Tecnológico.

\section{About the authors:}

1. Roberto Marx, PhD in Product Engineering, University of São Paulo, Brazil. E-mail: robemarx@usp.br.

2. João Paulo Reis Faleiros Soares, PhD in Product Engineering, University of São Paulo. Brazil.

E-mail: jpfaleiros@uol.com.br.

3. Lidyane Stephane da Silva Barros, Master Student of Product Engineering, University of São Paulo, Brazil.E-mail: lidyanebarros@usp.br.

\section{Contribution of each author:}

\begin{tabular}{lccc}
\hline Contribution & Roberto Marx & $\begin{array}{c}\text { Joáo Paulo Reis } \\
\text { Faleiros Soares }\end{array}$ & $\begin{array}{c}\text { Lidyane Stephane } \\
\text { da Silva Barros }\end{array}$ \\
\hline Definition of research problem & $\sqrt{ }$ & $\sqrt{ }$ & \\
Development of hypotheses or research questions (empirical studies) & $\sqrt{ }$ & $\sqrt{ }$ \\
3. Development of theoretical propositions (theoretical Work) & $\sqrt{ }$ & $\sqrt{ }$ \\
4. Theoretical foundation / Literature review & $\sqrt{ }$ & $\sqrt{ }$ \\
5. Definition of methodological procedures & $\sqrt{ }$ & $\sqrt{ }$ & \\
6. Data collection & & $\sqrt{ }$ \\
7. Statistical analysis & & $\sqrt{ }$ & \\
8. Analysis and interpretation of data & $\sqrt{ }$ & & $\sqrt{ }$ \\
9. Critical revision of the manuscript & $\sqrt{ }$ & $\sqrt{ }$ \\
10. Manuscript Writing & & & $\sqrt{ }$ \\
11. Other (Textual Revision / Formatting) & & & \\
\hline
\end{tabular}

